\title{
Inactivation of vitamins
}

\section{By H. KLÄUI, F. Hoffmann-La Roche \&ீ Co. Ltd, 4002-Basle, Switzerland}

Inactivation of vitamins may be the result of chemical reactions on the one hand or antimetabolites on the other. Although the subject of the symposium-'antinutritional factors'-is more closely, or almost exclusively, related to the antimetabolites, I should also like to include the stability aspects, i.e. the inactivation of vitamins due to intra- and intermolecular reactions induced by physical as well as chemical factors. It is assumed that this type of inactivation plays a major role in practical nutrition, and it is relatively well documented in a large number of publications, particularly during the last decade. However, in spite of all these publications, we still know very little as to the actual chemical mechanisms of the numerous reactions occurring in foods between vitamins and various components under different processing and environmental conditions.

The first part of this paper will deal with the specific anti-nutritional factors or compounds for the various vitamins, including antimetabolites and specific enzymes, such as thiaminases, or reagents such as $\mathrm{SO}_{2}$ for thiamine, and the second part with the more general effects of environmental factors, such as temperature, light and radiation in general, humidity, etc. With the exception of the biochemical antimetabolites, there is no clear distinction between a more specific or more general effect of these factors. The significant result is the same, namely, a partial or total inactivation of the vitamin by a structural interference with the molecule of the vitamin. In all these cases, therefore, chemical analysis is a satisfactory tool to measure the effect, whereas in the case of the pure antimetabolites the intact vitamin molecule may still be present and fully detectable. However, the biological effect is counteracted by the antivitamin and therefore lost, or at least reduced.

In the closer sense of the word, antimetabolites of vitamins are characterized by the following properties:

(a) Their application leads to the same deficiency symptoms occurring when the corresponding vitamin is missing.

(b) Addition of the corresponding vitamin eliminates these deficiency symptoms.

(c) Their chemical structure often bears a clear similarity to that of the corresponding vitamin.

One of the most recent surveys on antivitamins and antimetabolites is that of Somogyi (1973). He proposes to divide them into two groups:

(I) Structurally similar compounds, i.e. antivitamins as a specific type of antimetabolites. 
(2) Structure-modifying antivitamins, i.e. substances, mainly of biological origin, that destroy or decrease the effect of a vitamin by modifying the molecule itself or by forming complexes with the vitamin.

This classification parallels that used in enzymology for the inhibitors: the first group corresponds to the competitive inhibitors, the second to the non-competitive inhibitors.

The first report on antivitamin action deals with the observation that certain cereals were antagonistic to vitamin $\mathrm{D}$, and it was found later, that the antivitamin D substance is phytic acid, which inhibits the calcium absorption.

Another well-known observation was that of the antagonistic action of avidin against biotin, particularly noteworthy because the inhibitor was discovered first and the vitamin later. The inhibitor, a protein found in raw egg white, forms an insoluble complex with biotin.

A thiamine antagonist was found in the viscera of raw fish, after the corresponding vitamin $B_{1}$ deficiency had appeared in silver foxes fed on raw fish. In the meantime, enzymes which split thiamine at the methylene group have been isolated from a variety of animal, bacterial and vegetable sources (Kositawattanakul et al. 1977; De Kumar \& Chaudhuri, 1976; Murata et al. 1976; Sarkar \& Chaudhuri, 1976).

Between $194^{\circ}$ and $195^{\circ}$ investigations of antivitamins were greatly expanded when sulfonamides were shown to be antagonists of p-aminobenzoic acid. In addition to the naturally occurring antagonists studied, a large number of compounds resembling almost all of the vitamins were synthesized, but these unnatural compounds will not be considered here (Zymalkowski, 1957; Meunier, 1952; Fenner, 1972).

Antagonists of riboflavin are assumed to be the cause of a severe riboflavin deficiency established in patients who became ill after consumption of a Jamaican plum, (the ackeé plum). (5-Desaza- and 5-thiariboflavins, vitamin $B_{2}$ antimethabolites (Janda \& Hemmerich, I 976)).

Antagonists of niacin were suspected in maize, since people and experimental animals preponderantly receiving maize often show symptoms of niacin deficiency. Since chemical analysis indicates a rather good niacin content, it was suggested that the vitamin exists in maize in a bound form unavailable to man and animals.

Another mechanism of action was proposed by Gopalan, based on the observation that pellagra occurs in certain regions of India where millet constitutes the chief component of an otherwise protein-poor diet. Millet contains a sufficient content of free nicotinic acid but, like maize, it also has a high leucine content. It was suggested, therefore, that leucine interferes with niacin metabolism in amino acid imbalanced diets. However, as long as the factor or factors from wheat and maize, which cause the deficiency, are not known, it is not possible to decide whether a specific antivitamin action contributes to the appearance of these symptoms.

The inactivation of biotin by avidin from the raw white of avian eggs has already been briefly mentioned. It seems now that proteins that do have this 
capacity are much more widely distributed than had previously been assumed, and this, of course, raises the question of their significance.

A somewhat similar situation is assumed to exist with pyridoxine or vitamin $B_{6}$, where the hydrolytic cleavage product of a component occurring in flax seeds, l-amino-D-proline, forms a stable complex with pyridoxalphosphate, as does avidin with biotin. Here it may be added that ascorbic acid in prepared cabbage is present in the bound form, ascorbinogen, which is very poorly absorbed by man.

The case for other vitamins is not yet very clear. Vitamins which are very susceptible to oxidizing agents, such as vitamins $A, D$ and $E$ or to reducing agents, like vitamin $B_{12}$, may undergo reactions induced by traces of other food ingredients, a situation which is rather familiar to the food technologist. On the basis of currently available information, it is not possible to associate well defined, structure-related antagonists with the relatively large number of factors described to have properties antagonistic to the effect of vitamins $A, D$ and $E$.

Another point, however, which is of more general significance should be mentioned here. Vitamin $A$ has been described as an antagonist for vitamin $K$, and very large doses of vitamin $E$ are antagonistic for vitamin $A$ instead of showing an oxidation-preventing and thus vitamin $A$ sparing effect.

The reciprocal action between vitamin $A$ and $E$, and the interference of orally administered vitamin $A$ with the absorption of the $K$ vitamins shows clearly the importance of a well balanced diet. This obviously applies to the other antivitamin factors found so far as well. $A$ negative effect on nutritional status is to be feared only when the diet is extremely imbalanced. In times past a health movement claimed that man should live on milk and eggs, since these products were said to be those which nature had developed for the nourishment of offspring. It seems that these extremists abandoned their diet only when several cases of impaired sight had occurred, but I do not know whether this was the over-all effect of a biotin and perhaps another deficiency or another effect.

The stability of vitamins in foods is closely related to the properties of the vitamins, i.e. the stability per se, and to the shelf-life of foods in general; and of course it further depends on the actual conditions of processing, storage, cooking, and many interactions between food components and additives, and furthermore with a whole range of artefacts present in food. These products, including caramel, melanins and melanoidins and numerous Maillard reaction products, are formed either intentionally or unintentionally, and vitamins may play an important role in these systems:

Vitamin $\mathrm{C}$ is very reactive as an acid and as a reducing agent and is responsible for, or co-operates in, many browning reactions.

Vitamin $B_{1}$, and polyunsaturated fatty acids are involved in the typical meat odour and flavour.

Vitamin $B_{6}$ may take part in Maillard reactions.

This very complex situation is the reason why in assessing the nutritional status in the human the determination of the vitamin content must be done in the ready- 
to-eat meal, and why it cannot simply be calculated from tables (although the true absorbable vitamin content is still another problem).

When we now look at the food products and at the main factors causing food to change, we can say that bacteria, moulds, yeast and enzymatic breakdown are the main causes of deterioration of perishable foods. In addition to these biological reactions, various chemical reactions take place in all food, many involving oxygen, which is one of the main enemies of food (Table I). As in general most of these reactions are temperature sensitive, a most important factor in maintaining quality is a consistent low temperature. Since biological and most chemical reactions take place more readily in moist media than in dry, moisture is another enemy of stored foods.

\section{Table 1. A summary of the stability characteristics of the vitamins}

Vitamin $A$ and D

Vitamin E

Thiamine

Ribofiavin

Pyridoxine

Pantothenic acid compounds

Nicotinic acid and amide

Vitamin $B_{12}$

Biotin

Folic acid
Sensitive to oxidation. The oxidation is catalyzed by traces of metal, notably iron and copper

Relatively stable as the acetate or succinate ester

Sensitive to both oxidation and reduction. $\mathrm{pH}$ appears to be the chief factor in the decomposition of $B_{1}$

Relatively stable. Sensitive to light and alksline $\mathrm{pH}$

Relatively stable compound

Decomposed by hydrolysis. The rate is influenced by $\mathrm{pH}$

Relatively stable compounds

Decomposed by reducing agents. Decomposition influenced by $\mathrm{pH}$

Relatively otable compound

Sensitive to oxidizing and reducing agents, relatively stable only in dry form

In theory, this all sounds very clear and perhaps even easy, but how does it look in practice. What is the performance of vitamins in foods?

Here we have excellent and recent reviews by Bender (1978), De Ritter (1976) and a comprehensive monograph published by the American Medical Association (I974).

Considerable information is available on the effect of processing, different storage conditions, packaging etc. on the vitamin content of foods, and the results are not easily condensed into a few tables, since the variables are too numerous. The chief one is the vitamin content of raw foodstuffs.

This difficulty to draw reliable conclusions from the mass of information available, and the failure, in general, of attempts to study the kinetics of nutrient losses (since the simplified model conditions necessary for that purpose were often too different from the reality) may serve as an explanation, why it is desirable to give a very brief summary first, and then to discuss a few special cases in rather more detail.

Vitamin $C$ is the most reactive and thus the most labile of the nutrients (Tables 2, 3). Vitamin $A$ is also very susceptible, e.g. to oxidation, but it is not so reactive as ascorbic acid, and therefore it is much easier to stabilize the non-reactive vitamin 
A by coating it with protective films, such as gelatin, or embedding it in suitable carriers.

Table 2. Retention of vitamin $C(\%)$ during processing

Cooked, fresh peas

Scalding

Freezing

Thawing

Cooking

$\begin{array}{crrr}\text { Frozen } & \text { Canned } & \text { Air-dried } & \text { Freeze-dried } \\ 75 & \text { 70 } & 75 & 75 \\ 75 & \text { Canning 63 } & \text { Drying 45 } & \text { Drying 70 } \\ 71 & - & - & -75 \\ 39 & \text { Heating } 36 & \text { Cooking 25 } & \text { Cooking 35 }\end{array}$

Table 3. Effect of length of storage on the vitamin $C$ content of potatoes

\begin{abstract}
Main crop freshly dug
Main crop stored I -3 months

Main crop stored 4-5 months

Main crop stored 6-7 months

Main crop stored 8-9 months
\end{abstract}

Ascorbic acid (mg/ $100 \mathrm{~g})$

30
20
15
10
8

Loss of vitamin C can be diminished to a certain extent by good manufacturing practice. Its widespread use as a processing aid, as a stabilizer and antioxidant in many foods and drinks, as a dough improver in flour, and as a curing aid and colour stabilizer in meat products, compensates for these losses. In the case of meat products there may be a real benefit from processing, since a study carried out in Switzerland revealed that some elderly people may obtain a substantial part of their vitamin C supply from a popular type of sausage ('Cervelats') (Schlettwein-Gsell, 1975; Re: technical uses of vitamin C: Kläui, 1974 $a, b, 1976$ ).

In this brief summary vitamin $A$ and vitamin $B_{1}$ must be included. These two, together with vitamin $C$, are sometimes taken as indicators for the performance of other nutrients in new products or new processes. These three vitamins may be considered as representing to a certain degree the various stability profiles of the whole range of vitamins.

In conclusion a few special cases may be mentioned. Regarding the interaction between sulphites and thiamine, a scientific status summary by the Institute of Food Technologists' Expert Panel on Safety and Nutrition (1976) and the Committee on Public Information considers sulphites as safe provided the diet maintains an adequate thiamine level. It seems that the sulphite content of individual foods would probably not cause significant destruction of the thiamine content of the rest of the diet.

As mentioned in the tables, vitamin $B_{12}$ is sensitive to reducing agents, including vitamin C. Therefore, when Herbert \& Jacob (1974) reported the destruction of $5^{\circ}$ to $95 \%$ of the vitamin $B_{12}$ content of meals by $0.5 \mathrm{~g}$ of vitamin $\mathrm{C}$, this alarming statement was carefully examined, particularly in view of the relatively large-and steadily growing - amounts of vitamin C ingested. Fortunately, it turned out that 
the low vitamin $B_{12}$ values found by Herbert \& Jacob (1974) were entirely due to an unappropriate method of extraction. By using a standardized method for extraction and determination-corresponding in principle to that of the British Analytical Methods Committee-it was possible to prove that the intake of I $g$ of vitamin $C$ together with the meal did not decrease the vitamin $B_{12}$ content (Schindler \& Jäger, 1976).

Thermal processes are important for extending the storage life of foods, and have been used extensively in combination with other preservation techniques. The design of thermal processes in the food industry is governed by considerations in addition to nutrient retention. However, based on current industrial technology and practice, the food process industry is generally employing processes which result in maximum nutrient retention (Lund, 1977).

I should like to draw your attention to another special case, that of institutional feeding, and particularly to the problems connected with keeping prepared meals warm. The factor of primary importance in catering is microbiological hygiene, but organoleptic and nutritive aspects are almost as important. The vitamin stability pattern under these conditions is not significantly different from the general, but it should be kept in mind that keeping meals warm has a definite negative effect on the retention of vitamins, and it should therefore be limited or avoided if possible (Bowers \& Fryer, 1972; Fennema, 1977; Herrmann et al. 1974; Larousse, 1975; Nowak \& Paulus, 1977; Paulus, 1978; De Ritter et al. 1974; Rogowski, 1977; Zacharias, 1977; Zobel, 1971).

Finally there is evidence that the habit of smoking may affect the status of men and women as regards vitamins $\mathrm{B}_{6}, \mathrm{~B}_{12}, \mathrm{C}$ and nicotinamide (Brook \& Grimshaw, 1968; McGarry \& Andrews, 1972).

I have tried to show that the inactivation of vitamins in foods is obviously a very complex problem. Under so-called normal conditions, antivitamins (as competitive inhibitors) have practically no significance, whereas the chemical losses may be considerable. When advising the food manufacturer concerning the stability of vitamins in different foods and under various conditions, we usually consider the properties of the vitamins as well as earlier experience.

In conclusion, I would like to add that for the consumer, a well balanced diet, i.e. a diet including a variety of different foods from varying sources, and including vitamin-fortified food where necessary, is probably the best guarantee for supplying the complete range of macro- and micro-nutrients. All the vitamins needed would then be present in sufficient amounts, and an occasional antivitamin would be easily tolerated.

\section{REFERENCES}

American Medical Association (1974). Nutrients in processed foods, Vitamins-Minerals, Aston Mass: Publ. Sciences Gp Inc.

Bender, A. E. (1978). In Food Processing and Nutrition, p. 27. London: Academic Press.

Bowers, J. A. \& Fryer, B. A. (1972). Y. Am. Diet. Ass. 60, 399.

Brook, M. \& Grimshaw, J. J. (1968). Am. F. clin. Nutr. 21, I254.

De Kumar, B. 8c Chaudhuri, D. K. (1976). Int. Z. Vitam Forsch. 46, 154.

De Ritter, E. (1976). Fd Technol. 30, 48. 
De Ritter, E., Osadca, M., Scheiner, J. \& Keating, J. (1974). F. Am. Diet. Ass. 64, 391.

Fennema, O. (1977). Fd Technol. Lond. 31, 32.

Fenner, H. (1972). Pharmaxie unserer Zeit I, 81 .

Herbert, V. \& Jacob, E. (1974). F. Am. Diet. Ass. 230, 241.

Herrmann, K., Nebe, G. \& Suter, G. (1974). Ermähr.-Umsch. 21, 109.

Institute of Food Technologists Expert Panel (1976). Fd Trade Rev. 46, 76.

Janda, M. \& Hemmerich, P. (1976). Angew. Chem. 88, 475.

Kläui, H. (1974a). In Vitamin C, p. 16, [G. G. Birch and K. J. Parker editors], London: Applied Science Publishers.

Kläui, H. (1974b). In Natürliche und Synthetische Zusatzstoffe in der Nahrung des Menschen, CIIA Symposia; p. 62, Herausgeber: R. Ammon und J. Hollo, Dr. Dietrich Steinkopff Verlag, Darmstadt.

Kläui, H. (1976). In Int. Flavours, July/August, p. 165.

Kositawattanakul, T., Tosukhowong, P., Vimokesant, S. L. \& Panijpan, B. (1977). The Amer. Journal of Clinical Nutrition 30, 1686.

Larousse, J. (1975). Revue fr. Diët. 19, 7.

Lund, D. B. (1977). Fd Technol. 31, 71.

McGarry, J. M. \& Andrews, J. (1972). Br. med. F. 3, 74.

Meunier, P. (1952). In Fortschritte der Chemie organischer Naturstoffe 9, p. 88, Herausgeber: L. Zechmeister.

Murata, K., Yamaoka, M. \& Ichikawa, A. (1976). f. nutr. Sci. vitaminol. 22, (Suppl.) 7.

Nowak, I. \& Paulus, K. (1977). Lebensm. Wissenschaft und Technol. 10, 61.

Paulus, K. (1978). Lebensm. Technol. 2, 3.

Rogowski, B. (1977). Fleischwoirtschaft 56, 1789.

Sarkar, L. \& Chaudhuri, D. K. (1976). Int. Vitam Forsch. 46, 417.

Schindler, B. \& Jäger, A. (1976). Ernähr.-Umsch. 23, 342.

Schlettwein-Gsell, D. (1975). In Zur Ernährungssituation der schweizerischen Bevölkerung, [G. Brubacher and G. Ritzel, editors] Bern: Hans Huber.

Somogyi, J. C. (1973). In Toxicants occurring naturally in foods, Washington DC: National Academy of Sciences.

Zacharias, R. (1977). Errähr.-Umsch. 24, 304.

Zobel, M. (1971). Ernähr.-Umsch. 18, 374.

Zymalkowski, F. (1957). Dt. Apoth. Ztg. 17, 375. 